\section{Effectiveness of Biopolymer Horticultural Products for Production and Postproduction Nutrient Provision of Garden and Bedding Crops and Container Ornamentals}

\author{
James A. Schrader ${ }^{1,3,7}$, Christopher J. Currey ${ }^{1,4}$, Nicholas J. Flax ${ }^{1,5}$, \\ David Grewell ${ }^{2,6}$, and William R. Graves ${ }^{1,6}$
}

ADDITIONAL INDEX WORDs. biorenewable, bioplastics, sustainability, mineral nutrition, green technology

SUMMARY. We evaluated emerging biopolymer horticultural products that provide fertilizer nutrients to plants (fertilizing biocontainers, pelletized biopolymer fertilizer, and biopolymer fertilizer spikes) for their effectiveness during greenhouse production and garden growth of floriculture crops, and during postproduction culture of container ornamentals. Greenhouse experiments (in 4.5-inch containers) and garden trials were performed with tomato (Solanum lycopersicum), pepper (Capsicum annuum), petunia (Petunia $\times$ bybrida), and marigold (Tagetes patula). Postproduction experiments were performed with 12 -inch hanging baskets containing lobelia (Lobelia evinus), trailing petunia (Calibrachoa $\times$ bybrida), and petunia, and with 13-inch patio planters containing zonal geranium (Pelargonium $\times$ bortorum), spikes (Cordyline indivisa), bidens (Bidens ferulifolia), and trailing petunia. Although slightly less effective than synthetic controlled-release fertilizer (CRF), all three nutrient-containing biopolymer horticultural products were sufficient and suitable for providing fertilizer nutrients to plants grown in containers and in garden soil. Results of the postproduction experiment provided proof-of-concept for the effectiveness and potential of biopolymer fertilizer spikes as a sustainable method for providing fertilizer nutrients to containerized plants. The current formulation of pelletized biopolymer fertilizer was somewhat more effective for vegetable crops (pepper and tomato) than for floriculture crops (marigold and petunia). For plants produced in 4.5-inch containers, the combination of the fertilizing biocontainer with no additional fertilizer in the greenhouse, then burying the fertilizing container beneath the plant to degrade and provide nutrients in the garden was very effective. Biopolymer horticultural products represent a promising alternative to petroleum-based plastic containers and synthetic fertilizers. Adoption of some or all of these technologies could improve the environmental sustainability of the horticulture industry without reducing productivity or efficiency, and without increasing labor intensity.

$\mathrm{T}$ The extensive use of petroleumbased containers and synthetic fertilizers in horticulture provides unparalleled effectiveness (McCabe et al., 2014; Schrader et al., 2016), but this level of effectiveness is achieved through heavy consumption of finite fossil resources and with

This research was funded in part by the NSF - IUCRC Center for Bioplastics and Biocomposites, and by Iowa State University.

${ }^{1}$ Department of Horticulture, Iowa State University, Ames, IA 50011

${ }^{2}$ Department of Agricultural and Biosystems Engineering, Iowa State University, Ames, IA 50011

${ }^{3}$ Associate Scientist.

${ }^{4}$ Assistant Professor.

${ }^{5}$ Research Assistant.

${ }^{6}$ Professor.

${ }^{7}$ Corresponding author. E-mail: jschrade@iastate.edu.

https://doi.org/10.21273/HORTTECH03992-18 a disproportionate impact on the environment (Broschat, 1995; Montalbo-Lomboy et al., 2016; Wilson et al., 2010). Petroleum-based plastic containers are lightweight, strong, water-resistant, durable, and impact-resistant, and they can be molded into numerous shapes and colors for marketing of the plants grown in them (Schrader, 2016a). If environmental impact and consumption of finite resources were not a concern, petroleum-based plastics would be nearly perfect materials for horticulture containers. However, these materials are both nonrenewable and nonbiodegradable, issues that make their use unsustainable and a poor choice for single-use items such as horticulture containers. From a sustainable-design perspective, durable materials such as petroleumbased plastics are best used for durable goods, and when possible, single-use items should be made from materials that are less durable and come from renewable resources (Bhamra and Lofthouse, 2007). Horticulture containers must fulfill the functional requirements for effectively and efficiently growing plants under greenhouse and nursery conditions, but there is no need for the discarded, single-use containers to persist for hundreds of years in the environment.

Although some horticulturists have made efforts to recycle or reuse petroleum-based plastic containers, it is currently estimated that $98 \%$ of containers end up in the solid waste stream after only one use (Chappell and Knox, 2012; Kratsch et al., 2015). This practice results in the consumption and landfill disposal of more than 1 million tons of petroleum-based plastic in the form of horticulture containers each year in the United States (Schrader, 2013, 2016a). In a recent life cycle assessment comparing the cradle-to-gate environmental impacts of petroleumbased containers and nine types of biopolymer and biopolymer-composite containers, Montalbo-Lomboy et al. (2016) found that on a per-weight basis, the manufacture of petroleumbased plastic containers consumes between $86 \%$ and $171 \%$ more fossil fuel resources and produces between $3.5 \%$ and $35 \%$ higher global warming potential than does the manufacture of biocontainers made with formulations based on polylactic acid (PLA), a bioplastic produced from carbohydrate biomass. When considering these percentages on a scale of 1 million tons of

\begin{tabular}{llll}
\hline $\begin{array}{l}\text { Units } \\
\text { To convert U.S. to SI, } \\
\text { multiply by }\end{array}$ & U.S. unit & SI unit & $\begin{array}{l}\text { To convert SI to U.S., } \\
\text { multiply by }\end{array}$ \\
\hline 3.7854 & gal & $\mathrm{L}$ & 0.2642 \\
2.54 & inch $(\mathrm{es})$ & $\mathrm{cm}$ & 0.3937 \\
28.3495 & $\mathrm{Oz}$ & $\mathrm{g}$ & 0.0353 \\
28,350 & $\mathrm{Oz}$ & $\mathrm{mg}$ & $3.5274 \times 10^{-5}$ \\
0.9072 & $\operatorname{ton}(\mathrm{s})$ & $\mathrm{Mg}$ & 1.1023 \\
$\left({ }^{\circ} \mathrm{F}-32\right) \div 1.8$ & ${ }^{\circ} \mathrm{F}$ & ${ }^{\circ} \mathrm{C}$ & $\left({ }^{\circ} \mathrm{C} \times 1.8\right)+32$
\end{tabular}


plastic used per year, it is apparent that the potential for improving the sustainability of horticulture by adopting biopolymer containers is substantial. Along with the potential for strong improvements in sustainability for the containers themselves, biopolymer containers made from blends of PLA and soy (Glycine max) polymer can provide fertilizer nutrients to the plants growing in them, thereby reducing the amount of supplemental fertilizer required during plant culture and possibly after transplant if the container is crushed and buried near the plant roots (McCabe et al., 2016a; Schrader et al., 2013).

The issues with sustainability that result from extensive use of synthetic fertilizers are equally problematic. Synthetic water-soluble fertilizers are extremely effective for the production of horticulture crops but the amount of fossil fuel resources used to produce the fertilizer is very high, and because they are water soluble, the fertilizer nutrients are easily leached into runoff (Broschat, 1995; Wilson et al., 2010). Natural gas (a fossil fuel) is the resource most often used to provide hydrogen for making ammonia and other synthetic nitrogen $(\mathrm{N})$ fertilizers. In fact, most modern ammonia production facilities use natural gas as both "feed and fuel" for making fertilizer, and overall, $\mathrm{N}$ fertilizer production consumes $\approx 1 \%$ of the world's energy used each year (LeCompte, 2013). Along with extensive consumption of fossil fuel resources, worldwide ammonia fertilizer production is responsible for $\approx 5 \%$ of global carbon emissions, releasing $2 \mathrm{t}$ of carbon dioxide $\left(\mathrm{CO}_{2}\right)$ for every ton of ammonia produced (LeCompte, 2013). The biopolymer fertilizers evaluated in our research are made from nearly $100 \%$ biorenewable materials (McCabe et al., 2016b), meaning that almost none of the carbon or hydrogen comes from fossil resources. Likewise, when the carbon is released during use of the biopolymer fertilizer, there is little or no net increase in atmospheric $\mathrm{CO}_{2}$ because the original source of the carbon was $\mathrm{CO}_{2}$ harvested from the atmosphere by the corn (Zea mays) and soybean (G. max) plants whose seed is the feedstock for the production of the biopolymer nutrient materials. The energy savings realized by using the soy-based
$\mathrm{N}$ source is substantial. Instead of using fossil fuels and/or electricity to fix atmospheric $\mathrm{N}\left(\mathrm{N}_{2}\right)$ to make ammonia (the Haber-Bosch process), the $\mathrm{N}_{2}$ fixation for biopolymer fertilizer is performed in the root nodules of soybean plants through a symbiotic relationship with $R h i z 0^{-}$ bia bacteria, and the energy for this natural process is provided by the sun through photosynthesis (Calabria et al., 2012; McCabe et al., 2016b; Sawyer et al., 2010; Schrader et al., 2013).

Leaching of synthetic water-soluble fertilizers is a growing concern for the greenhouse and nursery industries (Broschat, 1995; Wilson et al., 2010), and investigations of production practices have demonstrated that leaching of fertilizer nutrients can be reduced by using CRFs in place of watersoluble, solution fertilizers (Yeager et al., 1993). The soy-based biopolymer fertilizers, fertilizer spikes, and fertilizing biocontainers evaluated in this report are novel types of CRF. Unlike standard CRFs that are prills of synthetic fertilizer coated with petroleum-based plastics, biopolymer fertilizers are made from homogenized, nutrient-containing bioplastic material that is either molded into a container or spike, or is pelletized into a granular form (Fig. 1). Like standard CRFs, biopolymer fertilizers release nutrients slowly, and thus reduce nutrient loss in leachate compared with water-soluble fertilizers (Calabria et al., 2012; McCabe et al., 2016a, 2016b).

In this study, we investigated the effectiveness of sustainable biopolymer horticultural products (fertilizing biocontainers, pelletized biopolymer fertilizer, and biopolymer fertilizer spikes) for meeting the nutrient requirements of plants during production and postproduction. The four main objectives of our research were to 1) determine the effectiveness of biopolymer horticultural products for meeting the needs of select specialty crops through greenhouse production, garden growth, and fruit/vegetable harvest; 2) determine the effectiveness of granular biopolymer fertilizer and biopolymer fertilizer spikes for postproduction performance (period after consumer purchase) of select ornamental crops; 3) quantify nutrient uptake by plants when using biopolymer products; and 4) compare the effectiveness of the biopolymer products to that of the current standard products and practices (petroleum-based plastic containers and synthetic CRF).

\section{Materials and methods}

We evaluated the effectiveness of biopolymer horticultural products in two experiments. The first experiment examined the performance of biopolymer containers and pelletized biopolymer fertilizer during greenhouse production and garden growth of two common garden crops (pepper and tomato) and two common bedding crops (marigold and petunia). The second experiment examined the performance of pelletized biopolymer fertilizer and biopolymer fertilizer spikes on the postproduction growth and health of container ornamentals in 12 -inch hanging baskets and 13 -inch patio planters. Control treatments for both experiments included a treatment with no fertilizer and treatments with standard synthetic CRF.

The materials for pelletized biopolymer fertilizer, biopolymer fertilizer spikes, and fertilizing biopolymer containers were blends of PLA and soy polymer with adipic acid plasticizer (SP.A). The blend ratio for both the pelletized fertilizer and fertilizer spikes was $60 \%$ SP.A to $40 \%$ PLA. The blend ratio for the bioplastic material used for fertilizing biocontainers was 55\% PLA, 35\% SP.A, and 10\% distillers dried grains with solubles (DDGS). The granular DDGS material is a nutrient-containing coproduct of corn ethanol production that blends well with bioplastics. Detailed formulations and descriptions of pilot-scale manufacture of biopolymer containers and pelletized fertilizer are available in McCabe et al. (2016a, 2016b), respectively. Biopolymer fertilizer spikes were manufactured by using methods similar to those used for making containers, but were formed with a different injection mold.

Expt. 1: Evaluation of BIOPOLYMER CONTAINERS AND PELLETIZED BIOPOLYMER FERTILIZER DURING GREENHOUSE PRODUCTION AND GARDEN GROWTH. This experiment had two phases, a greenhouse production phase and a garden growth phase. Pelletized biopolymer fertilizer was evaluated in both phases as was the fertilizing biocontainer made of soy-based material 

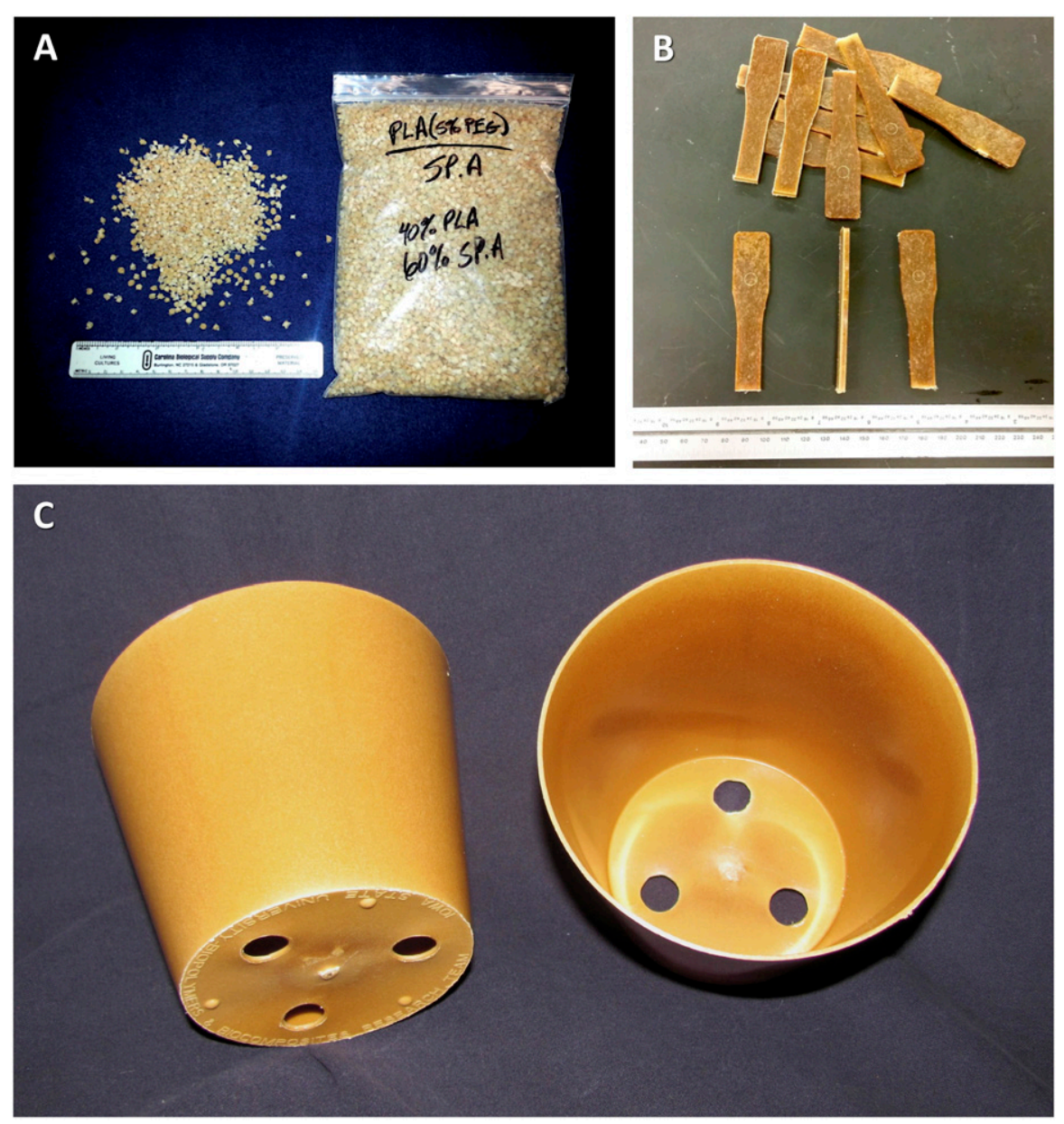

Fig. 1. The three types of biopolymer fertilizing products evaluated in this study are as follows: (A) pelletized biopolymer fertilizer made of polylactic acid (PLA) and soy polymer with adipic acid plasticizer (SP.A) blended $40 \%$ to $60 \%$ by weight; (B) biopolymer fertilizer spikes made of PLA-SP.A blended $40 \%$ to $60 \%$ by weight; and $(\mathrm{C})$ fertilizing biocontainers made of PLA-SP.A blended $50 \%$ to $50 \%$ by weight; Bio = made from bio-based material (nonpetroleum).

that releases nutrients and can biodegrade in soil. The experimental design for both phases was a randomized complete block design (blocked by species). Species grown in Expt. 1 were pepper, tomato, marigold, and petunia. The treatment design for both phases was a factorial, with treatments for container type crossed with treatments for fertilizer type. In the greenhouse phase, plants were grown in 4.5-inch-diameter round containers filled with peat-based soilless substrate (Sunshine ${ }^{\circledR}$ LB-2; Sun Gro Horticulture, Agawam, MA) for 6 weeks, at which time four replications (individual plants) from each factorial treatment combination were harvested for dry weights and nutrient content measurements, and the remaining eight replications for each factorial treatment were transplanted into the garden plot and grown for 9 weeks. The greenhouse phase was performed in a glass-glazed greenhouse without supplemental lighting from 13 Apr. to 25 May, and experimental units were hand-irrigated as needed. Air temperature was maintained at $25 \pm 6{ }^{\circ} \mathrm{C}$, relative humidity $(\mathrm{RH})$ ranged from $28.4 \%$ to $79.8 \%($ mean $=59.8 \%)$, and the mean photosynthetically active radiation measured at $1200 \mathrm{HR}$ was $635 \mu \mathrm{mol} \cdot \mathrm{m}^{-2} \cdot \mathrm{s}^{-1}$ during the greenhouse phase. The garden phase was performed from 26 May to 28 July at a research farm near Ames, IA. The soil was a Clarion loam, fine-loamy, mixed, superactive, mesic Typic Hapludoll, and plots were irrigated uniformly with overhead irrigation to provide $\approx 1$ inch of water per week to supplement naturally occurring rainfall. Temperature ranged from 9.9 to $34.3{ }^{\circ} \mathrm{C}$ (mean = $23.3{ }^{\circ} \mathrm{C}$ ) during the garden experiment, and $\mathrm{RH}$ ranged from $27.9 \%$ to $100 \%($ mean $=75.9 \%)$.

Three types of containers were used as treatments in the greenhouse phase: a fertilizing biocontainer (PLA-SP.A-DDGS 55/35/10), a nonfertilizing (NF) biocontainer (PLA only), and a standard petroleum-based plastic container (polypropylene). The three container types are described and illustrated in Fig. 2. A partial factorial was used to cross the three container treatments with three fertilizer treatments (pelletized biopolymer fertilizer, synthetic granular CRF, and no-fertilizer control). The synthetic fertilizer for Expt. I was $18 \mathrm{~N}-2.6 \mathrm{P}-6.7 \mathrm{~K}$ synthetic CRF (Nutricote ${ }^{\circledR}$ 18-6-8; Florikan, Sarasota, FL). The amount for both fertilizer types was based on the $\mathrm{N}$ supplied and was chosen according to the recommended application amount for the synthetic CRF. This enabled the application of the two fertilizers at the same standard amount of $\mathrm{N}$. The amounts of elemental $\mathrm{N}$, phosphorus $(\mathrm{P})$, and potassium $(\mathrm{K})$ applied per 4.5-inch container for synthetic CRF were (in grams) $0.32 \mathrm{~N}$, $0.05 \mathrm{P}$, and $0.12 \mathrm{~K}$; and the amounts applied per 4.5-inch container for biopolymer fertilizer were $0.32 \mathrm{~N}$, $0.03 \mathrm{P}$, and $0.09 \mathrm{~K}$. The granular fertilizers (both synthetic CRF and pelletized biopolymer fertilizer) were incorporated into the peat-based substrate by mixing the granules with the substrate individually for each experimental unit, inserting the plug seedling, and then irrigating to container capacity.

At the end of the greenhouse phase of the experiment (after 6 weeks of growth), all experimental units were ascribed a visual rating for plant health (blind rating by two experienced horticulturists on a scale of $0=$ worst $/$ dead to $5=$ best). Indicators of poor health that resulted in lower ratings included chlorosis, necrosis, and stunted growth. Four randomly selected replications were harvested from each container-fertilizer factorial treatment, plants were washed of medium, and samples were prepared and dried at $67^{\circ} \mathrm{C}$ for $3 \mathrm{~d}$. Dried plants were held for $24 \mathrm{~h}$ in ambient conditions before measuring total plant dry weight (shoot + root dry weight) of each sample. After recording dry weights, samples of dry tissue were 

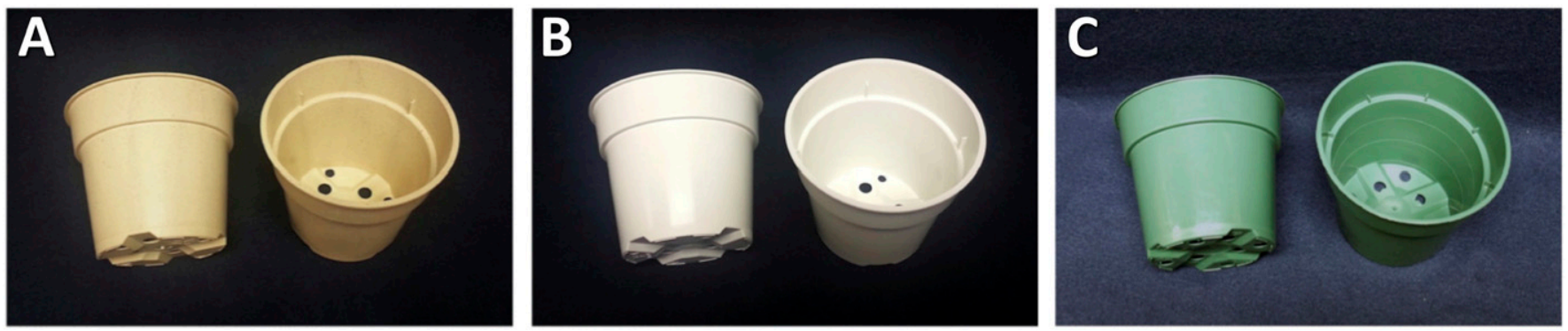

Fig. 2. Container types used in Expt. 1 are as follows: (A) fertilizing biocontainer made from polylactic acid (PLA), soy polymer with adipic acid plasticizer, and distillers dried grains with solubles blended at a ratio of 55/35/10 by weight; (B) nonfertilizing biocontainer made of recycled PLA; and (C) petroleum-based control container made of polypropylene; Bio = made from bio-based material (nonpetroleum).

prepared and submitted to a commercial laboratory (AgSource Harris Laboratories, Lincoln, NE) for analysis of nutrient concentration ( $\mathrm{N}, \mathrm{P}$, and $\mathrm{K}$ ). Because all foliage nutrient concentrations, except those of plants in the nofertilizer control treatments, were within established standards for quality bedding plant production according to Bryson et al. (2014), we focused our analyses on plant nutrient content (uptake) rather than nutrient concentration. Plant nutrient content (milligrams) was calculated by multiplying the concentration of each nutrient (milligrams per gram) in dried tissue by the dry weight of the plant (grams).

In the garden phase of the experiment, the treatment design was a partial factorial that crossed greenhouse treatments (container type + fertilizer treatment) with the fertilizer treatments applied in the garden plot. Similar to the greenhouse phase, the amount for both granular fertilizer types was based on the $\mathrm{N}$ supplied and was chosen according to the recommended application amount for synthetic CRF. This enabled the application of the two fertilizers at the same standard amount of $\mathrm{N}$. The amounts of elemental N, P, and K applied per plant for synthetic CRF were (in grams) $0.84 \mathrm{~N}, 0.12 \mathrm{P}$, and $0.31 \mathrm{~K}$; and the amounts applied per plant for biopolymer fertilizer were $0.84 \mathrm{~N}, 0.09 \mathrm{P}$, and $0.25 \mathrm{~K}$. The granular fertilizers (both synthetic CRF and pelletized biopolymer fertilizer) were incorporated into the soil directly adjacent to the root system of the transplant by first mixing the granules with the soil in the planting hole and then installing the plant and irrigating with $\approx 2 \mathrm{~L}$ of water. Treatments that had supplemental nutrients provided by the used fertilizing biocontainer material were established by crushing the used container, mixing the broken pieces of the container into the soil in the bottom of the planting hole, and then installing the plant and irrigating as previously described. After 9 weeks of growth, all experimental units were ascribed a visual rating for plant health as described in methods for the greenhouse phase. For pepper and tomato, fruit production was measured by counting the number of fruit greater than 1 inch in diameter on each plant. Likewise, flower production was quantified on marigold and petunia by counting the number of flowers that were fully open on each plant. The shoot of each plant was severed at the soil surface, dried, and measured for dry weight as described in methods for the greenhouse phase.

Expt. 2: Evaluation OF PELLETIZED BIOPOLYMER FERTILIZER AND BIOPOLYMER FERTILIZER SPIKES ON POSTPRODUCTION GROWTH AND HEALTH OF CONTAINER ORNAMENTALS. This experiment was performed with two types of containers (12-inch diameter hanging baskets and 13-inch diameter patio planters), each holding multiple herbaceous species that were purchased at marketable size and quality. The 12-inch hanging baskets contained petunia, lobelia, and trailing petunia. The 13 -inch patio planters contained spikes, geranium, bidens, and trailing petunia. Treatments included two application amounts each for the pelletized biopolymer fertilizer, the biopolymer fertilizer spikes, and the synthetic CRF. The application amounts were calculated to be $100 \%$ of the recommended application amount of $\mathrm{N}$ and $75 \%$ of the recommended application amount of N. Synthetic fertilizer for Expt. 2 was $15 \mathrm{~N}-3.9 \mathrm{P}-10 \mathrm{~K}$ synthetic CRF (Osmocote ${ }^{\circledR}$ Plus 15-912; Everris, Geldermalsen, The Netherlands). As with Expt. 1, application amounts for the two granular fertilizers were based on the $\mathrm{N}$ supplied at the recommended application amount for synthetic CRF, which enabled the two fertilizers to be applied at the same standard amount of N. For hanging baskets, the amounts of elemental $\mathrm{N}, \mathrm{P}$, and $\mathrm{K}$ applied per container for synthetic CRF were (in grams) $3.8 \mathrm{~N}$, 1.0 P, and $2.5 \mathrm{~K}$ for the $75 \%$ application; and $5.4 \mathrm{~N}, 1.4 \mathrm{P}$, and $3.6 \mathrm{~K}$ for the $100 \%$ application. The amounts of elemental N, P, and $\mathrm{K}$ applied per container for biopolymer fertilizer were (in grams) $3.8 \mathrm{~N}, 0.4 \mathrm{P}$, and $1.1 \mathrm{~K}$ for the $75 \%$ application; and $5.4 \mathrm{~N}, 0.6 \mathrm{P}$, and 1.6 $\mathrm{K}$ for the $100 \%$ application. For patio planters, the amounts of elemental $\mathrm{N}, \mathrm{P}$, and $\mathrm{K}$ applied per container for synthetic CRF were (in grams) $6.2 \mathrm{~N}$, 1.6 $\mathrm{P}$, and $4.1 \mathrm{~K}$ for the $75 \%$ application; and $9.2 \mathrm{~N}, 2.4 \mathrm{P}$, and $6.1 \mathrm{~K}$ for the $100 \%$ application. The amounts of elemental N, P, and $\mathrm{K}$ applied per container for biopolymer fertilizer were (in grams) $6.2 \mathrm{~N}, 0.6 \mathrm{P}$, and $1.8 \mathrm{~K}$ for the $75 \%$ application; and 9.2 N, 0.9 P, and $2.7 \mathrm{~K}$ for the $100 \%$ application. Because the biopolymer fertilizer spikes were prototypes being evaluated for the first time, there were no recommendations available for application amounts (number of spikes). The numbers of spikes for treatments were chosen arbitrarily to be four and six spikes for the patio planter and two and four spikes for the hanging baskets.

The experimental design for Expt. 2 was a randomized complete block design (blocked by container size), and there were seven treatments 
applied to each block (two application amounts of three fertilizers and a control with no fertilizer). The granular fertilizers were applied as a top dressing, and the fertilizer spikes were spaced evenly around the inside of the containers, inserted vertically into the root substrate $\approx 7 \mathrm{~cm}$ from the inside wall of the container. Experimental units were arranged randomly on expanded metal platforms raised $15 \mathrm{~cm}$ from the ground and located between two greenhouses. Experimental units received unobstructed sunlight each day from $\approx 1000$ to $1300 \mathrm{HR}$. Units were irrigated uniformly with water as needed. The daily light integral during the experiment was $38.5 \pm 12.3$, and the mean daily temperature was $24.3 \pm 5.8^{\circ} \mathrm{C}$. After 16 weeks (20 May to 9 Sept.), units were ascribed a visual rating for plant health, and plants were harvested, dried, measured for dry weight, and analyzed for nutrient content as described in methods for Expt. 1.

Statistical analyses. Means for measured parameters were quantified to characterize and compare the effectiveness of experimental treatments for meeting the nutrient requirements of plants. Data were analyzed for main effects, interactions, and means separation by using $\mathrm{JMP}^{\circledR}$ Pro statistical software (version 11.0.0; SAS Institute, Cary, NC). Means separation analyses were conducted by using Tukey-Kramer honestly significant difference model $(P \leq$ $0.05)$. Factorial interactions were significant in both experiments; therefore results for factorial treatments are presented in full cross-classification. For Expt. 1 results, interaction analysis showed $P=0.0009$ for the greenhouse phase and $P=0.0013$ for the garden phase. For Expt. 2 results, interaction analysis showed $P=$ 0.0024 . Because of the complexity of factorial treatments for the garden phase of Expt. 1, we simplified our results for presentation by combining results for the two ornamental bedding crops (marigold and petunia) and combining the results of the two garden crops (pepper and tomato). Individual values were normalized separately for each species to provide unweighted means on a scale of 0 to 100 (Pyle, 1999). This function yielded scores for effectiveness based on the three measured parameters and allowed results to be presented as grouped columns in the same bar chart. Normalization of individual values was accomplished by using the formula: $\mathrm{a}+(\mathrm{X}-\mathrm{A})(\mathrm{b}-\mathrm{a}) /$ $(\mathrm{B}-\mathrm{A})$ where $\mathrm{A}=$ minimum of original data set, $\mathrm{B}=$ maximum of original data set, $\mathrm{a}=$ minimum of normalized data set $(0), b=$ maximum of normalized data set (100), and X = the original individual value (Pyle, 1999).

\section{Results and discussion}

In the greenhouse evaluations of Expt. 1, all results for plants grown with pelletized biopolymer fertilizer, fertilizing biocontainers, and synthetic CRF treatments were superior to those of plants grown in the nofertilizer control treatment for all four species used in the evaluation (Table 1). These results demonstrate that pelletized biopolymer fertilizer and fertilizing biocontainers both provide nutrients to plants during greenhouse production. In general, plants provided with synthetic CRF were slightly larger and healthier than plants that received biopolymer fertilizer. For tomato and marigold, plant health rating was slightly higher for plants grown with synthetic CRF than for those grown with pelletized biopolymer fertilizer, but for pepper and petunia, there was no difference between health ratings for plants that received these two treatments (Table 1 ). The greater effectiveness of synthetic CRF was more evident with results of plant dry weight, in which plants grown with synthetic CRF accumulated greater dry weights than those grown with pelletized biopolymer fertilizer or fertilizing biocontainers for all four species (Table 1). For pepper and tomato, health ratings were slightly better for plants grown with pelletized biopolymer fertilizer than for those grown with the fertilizing biocontainer and no additional fertilizer, but this was the only comparison that showed the fertilizing biocontainers to be slightly less effective than the other biofertilizer treatments (Table 1). In all other comparisons of plant growth and health, the results for fertilizing biocontainers were similar to those of the pelletized biopolymer fertilizer under greenhouse conditions.

Based on the results for nutrient content of plants at the end of greenhouse production, both biopolymer fertilizer products (pelletized fertilizer and fertilizing biocontainer) were effective for providing primary macronutrients (Table 1). Although $\mathrm{N}, \mathrm{P}$, and $\mathrm{K}$ contents were generally greater for plants grown with synthetic CRF than for those grown with biopolymer fertilizer, the differences were often not significant and some of the biopolymer fertilizer treatments yielded higher nutrient contents than synthetic CRF for particular species. Pepper, for example, had the highest $\mathrm{N}$ and $\mathrm{P}$ contents when grown in fertilizing biocontainers and provided pelletized biopolymer fertilizer, and tomato had the highest $\mathrm{N}$ content when grown in petroleum-based PP containers and fertilized with pelletized biopolymer fertilizer (Table 1). Of the three macronutrients, $\mathrm{P}$ was the one most often lower in plants grown with biopolymer fertilizer compared with those grown with synthetic CRF. However, this is not unexpected considering that the formula for the biopolymer fertilizer provided $29 \%$ less $\mathrm{P}$ than that of synthetic CRF. In 4.5inch containers, unrounded values of $\mathrm{P}$ applied per container were 0.0328 and $0.0465 \mathrm{~g}$ from biopolymer fertilizer and synthetic CRF, respectively. As described in the methods section, the amounts of the biopolymer and synthetic fertilizers were chosen to provide the same amount of $\mathrm{N}$ from both fertilizers because $\mathrm{N}$ is commonly required in greater quantities by crops than any of the other essential nutrients (Mengel and Kirkby, 2001). Therefore, the lower proportions of $\mathrm{P}$ and $\mathrm{K}$ in biopolymer fertilizer was a condition of our experimental design and could explain many of the lesser results received for plants provided with biopolymer fertilizer compared with those provided with synthetic CRF. Even though our choice to match the $\mathrm{N}$ content of the two fertilizers was valid and justified, it is probable that plants would have responded better to biopolymer fertilizer if it had been provided at an amount that supplied more $\mathrm{P}$ and $\mathrm{K}$.

There were no noteworthy differences between the effects of $\mathrm{NF}$ biocontainers and those of the petroleum-based polypropylene (PP) containers (Table 1 ), providing further confirmation that NF PLA biocontainers can be used as drop-in replacements for petroleum-based 
Table 1. Health rating, dry weight, and nutrient content [nitrogen $(\mathrm{N})$, phosphorus $(\mathrm{P})$, and potassium (K)] of four popular greenhouse crops grown with biopolymer horticultural products, synthetic controlled-release fertilizer, or a no-fertilizer control treatment. Plants were grown for 6 weeks in 4.5 -inch $(11.43 \mathrm{~cm})$ diameter round containers filled with peat-based soilless substrate. Results are reported in factorial, with treatments for container type crossed with treatments for fertilizer type.

\begin{tabular}{|c|c|c|c|c|c|}
\hline \multirow[b]{2}{*}{ Treatment $^{\mathrm{z}}$} & \multirow[b]{2}{*}{ Plant health rating ( 0 to 5 scale $)^{y}$} & \multirow[b]{2}{*}{ Plant dry wt $(g)^{x}$} & \multicolumn{3}{|c|}{ Plant nutrient content $(\mathrm{mg})^{x}$} \\
\hline & & & $\mathbf{N}$ & $\mathbf{P}$ & $\mathbf{K}$ \\
\hline \multicolumn{6}{|l|}{ Tomato } \\
\hline Fert biocontainer + No Fert & $3.4 \mathrm{~d}^{\mathrm{w}}$ & $5.2 \mathrm{~b}$ & $128 \mathrm{c}$ & $16 \mathrm{~b}$ & $102 \mathrm{bc}$ \\
\hline Fert biocontainer + Bio Fert & $4.4 \mathrm{~b}$ & $4.3 \mathrm{~b}$ & $160 \mathrm{bc}$ & $13 \mathrm{bc}$ & $86 \mathrm{~cd}$ \\
\hline NF biocontainer + Bio Fert & $4.4 \mathrm{~b}$ & $4.6 \mathrm{~b}$ & $184 \mathrm{ab}$ & $10 \mathrm{~d}$ & $80 \mathrm{~d}$ \\
\hline NF biocontainer + Synth Fert & $4.5 \mathrm{a}$ & $7.3 \mathrm{a}$ & $176 \mathrm{ab}$ & $22 \mathrm{a}$ & $127 \mathrm{a}$ \\
\hline PP container + No Fert & $2.8 \mathrm{e}$ & $3.7 \mathrm{c}$ & $48 \mathrm{~d}$ & $9 \mathrm{~d}$ & $55 \mathrm{e}$ \\
\hline \multicolumn{6}{|l|}{ Pepper } \\
\hline Fert biocontainer + No Fert & $3.1 \mathrm{~d}$ & $4.5 \mathrm{c}$ & $107 \mathrm{c}$ & $18 \mathrm{ab}$ & $148 \mathrm{~b}$ \\
\hline Fert biocontainer + Bio Fert & $4.2 \mathrm{a}$ & $6.0 \mathrm{~b}$ & $244 \mathrm{a}$ & $21 \mathrm{ab}$ & $186 \mathrm{a}$ \\
\hline NF biocontainer + Bio Fert & $4.3 \mathrm{a}$ & $5.6 \mathrm{bc}$ & $185 \mathrm{~b}$ & $16 \mathrm{~b}$ & $106 \mathrm{c}$ \\
\hline NF biocontainer + Synth Fert & $3.8 \mathrm{c}$ & $8.2 \mathrm{a}$ & $187 \mathrm{~b}$ & $24 \mathrm{a}$ & $141 \mathrm{~b}$ \\
\hline \multicolumn{6}{|l|}{ Petunia } \\
\hline Fert biocontainer + No Fert & $3.9 \mathrm{~b}$ & $4.9 \mathrm{~b}$ & $114 \mathrm{c}$ & $13 \mathrm{c}$ & $128 \mathrm{abc}$ \\
\hline Fert biocontainer + Bio Fert & $3.9 \mathrm{ab}$ & $4.1 \mathrm{~b}$ & $130 \mathrm{ab}$ & $14 \mathrm{c}$ & $118 \mathrm{abc}$ \\
\hline NF biocontainer + Bio Fert & $3.7 \mathrm{bc}$ & $4.4 \mathrm{~b}$ & $122 \mathrm{bc}$ & $11 \mathrm{c}$ & $72 \mathrm{~d}$ \\
\hline NF biocontainer + Synth Fert & $4.2 \mathrm{a}$ & $7.4 \mathrm{a}$ & $195 \mathrm{a}$ & $26 \mathrm{a}$ & $145 \mathrm{a}$ \\
\hline PP container + Bio Fert & $3.6 \mathrm{c}$ & $4.5 \mathrm{~b}$ & $131 \mathrm{ab}$ & $15 \mathrm{bc}$ & 99 bcd \\
\hline PP container + Synth Fert & $3.9 \mathrm{~b}$ & $6.9 \mathrm{a}$ & $172 \mathrm{ab}$ & $20 \mathrm{ab}$ & $131 \mathrm{ab}$ \\
\hline PP container + No Fert & $2.7 \mathrm{~d}$ & $3.5 \mathrm{c}$ & $64 \mathrm{~d}$ & $14 \mathrm{c}$ & $84 \mathrm{~cd}$ \\
\hline \multicolumn{6}{|l|}{ Marigold } \\
\hline Fert biocontainer + No Fert & $4.2 \mathrm{bc}$ & $4.2 \mathrm{ab}$ & $117 \mathrm{~b}$ & $16 \mathrm{c}$ & $135 \mathrm{ab}$ \\
\hline Fert biocontainer + Bio Fert & $4.2 \mathrm{bc}$ & $3.4 \mathrm{~b}$ & $157 \mathrm{ab}$ & $18 \mathrm{c}$ & $107 \mathrm{~b}$ \\
\hline NF biocontainer + Bio Fert & $4.1 \mathrm{c}$ & $3.8 \mathrm{~b}$ & $178 \mathrm{a}$ & $17 \mathrm{c}$ & $115 \mathrm{~b}$ \\
\hline
\end{tabular}

${ }^{\mathrm{z}}$ Fert $=$ fertilizing or fertilizer; Bio $=$ made from bio-based material (nonpetroleum); NF = nonfertilizing; Synth = synthetic; PP $=$ petroleum-based polypropylene.

${ }^{y}$ Health rating was a visual rating by two experienced horticulturists on a scale of $0=$ worst to $5=$ best.

${ }^{\mathrm{x}} 1 \mathrm{~g}=0.0353 \mathrm{oz}, 1 \mathrm{mg}=3.5274 \times 10^{-5} \mathrm{oz}$

${ }^{\mathrm{w}}$ Means within a column followed by the same letter are not different according to Tukey-Kramer honestly significant difference test at $P \leq 0.05$ ( $n=12$ for health rating, $n=4$ for dry weight, $\mathrm{N}, \mathrm{P}$, and $\mathrm{K})$. Results for each species were analyzed separately.

containers during greenhouse production, requiring no changes to cultural practices (McCabe et al., 2016c; Schrader, 2016b). Comparing the results of the PP container with no fertilizer with the results for the fertilizing biocontainer with no fertilizer demonstrates that the fertilizing biocontainer provided nutrients to plants and facilitated good health and growth for all four species (Table 1). Compared with treatments with pelletized biopolymer fertilizer, fertilizing biocontainers with no supplemental fertilizer were only slightly less effective at promoting growth and should be considered as a viable option for production of short- and medium-cycle greenhouse crops. Although plants grown in fertilizing biocontainers with no supplemental fertilizer were slightly smaller and slightly lighter green, nutrient uptake was sufficient (Table 1). Use of fertilizing biocontainers for greenhouse crops could be among the most sustainable ways to both hold the plants (provide the containers) and provide them with nutrients, achieving both functions with one sustainable product.

The garden evaluations of Expt. 1 were designed to provide results of the cumulative effects of the greenhouse treatments and the garden treatments. The plants were first grown in the greenhouse under randomly assigned treatments and then the plants were transplanted into the garden plots and randomly assigned fertilizer treatments for nutrient provision during garden culture. Results of these cumulative effects from greenhouse through garden harvest are presented in Fig. 3, with greenhouse treatments in parentheses (container type + fertilizer type), followed by the garden treatment (fertilizer type). To reduce the size of the factorial results so they could be more easily understood, the results for the two garden crops (pepper and tomato) were combined and the results for the two ornamentals (marigold and petunia) were combined. 
Effectiveness with Pepper and Tomato (Mean Normalized Scores 0 to 100)

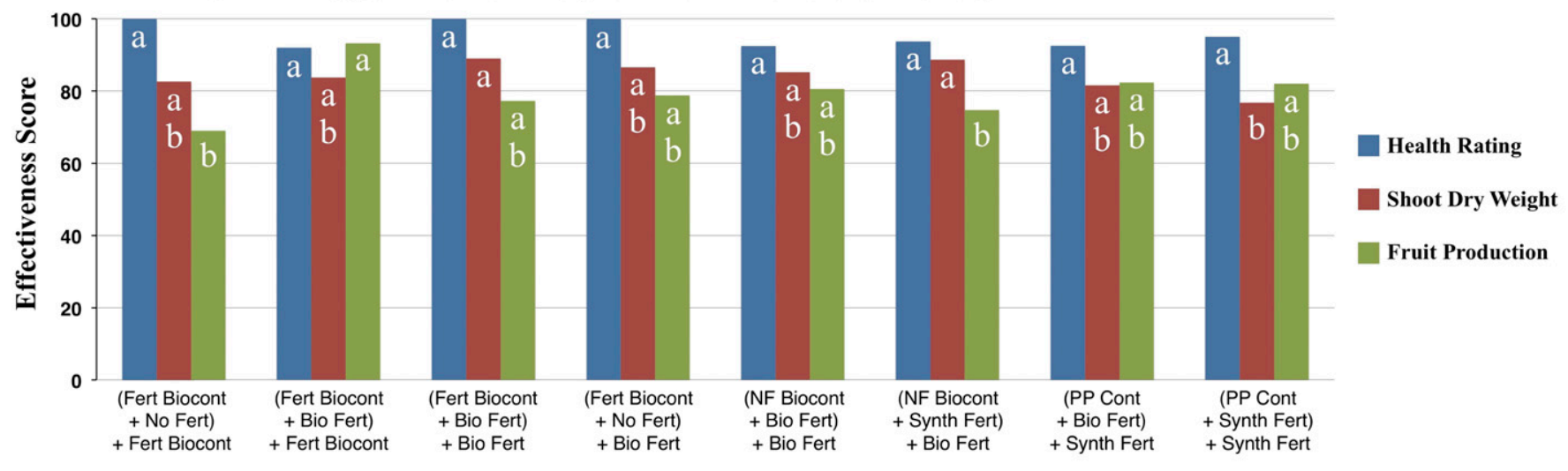

Effectiveness with Marigold and Petunia (Mean Normalized Scores 0 to 100)

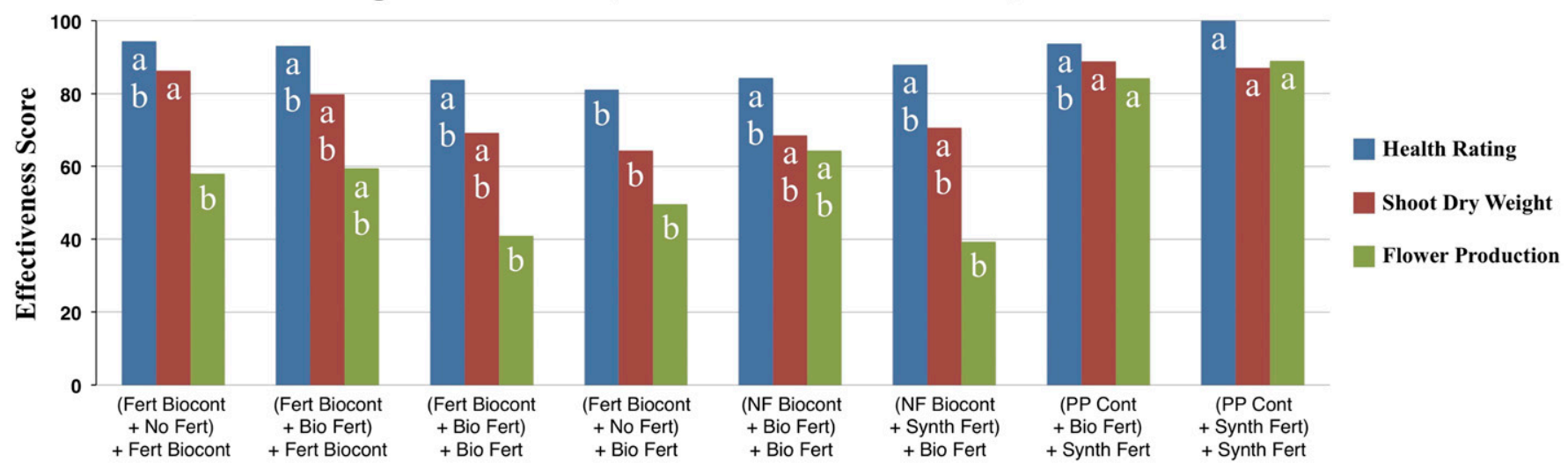

Fig. 3. Cumulative effects of greenhouse and garden treatments on the health rating, shoot dry weight accumulation, and fruit (pepper and tomato) or flower (marigold and petunia) production measured at the end of 9 weeks of garden culture. Results are reported in factorial, with treatments for container type and fertilizer type from greenhouse production shown in parentheses, followed by the fertilizer type used in the garden phase. Health rating was a visual rating by two experienced horticulturists on a scale of $0=$ worst to $5=$ best. For pepper and tomato, fruit production was measured by counting the number of fruit greater than 1 inch $(2.5 \mathrm{~cm})$ in diameter on each plant. Flower production was quantified on marigold and petunia by counting the number of flowers that were fully open on each plant. Because of the complexity of factorial treatments for the garden phase, we simplified our results for presentation by combining results for the two vegetable crops (pepper and tomato) and combining results for the two floriculture crops (marigold and petunia). Bars of the same color that are marked with the same letter are not different according to Tukey-Kramer honestly significant difference test at $P \leq 0.05$; Fert = fertilizing or fertilizer; Bio $=$ made from bio-based material $($ nonpetroleum); Biocont $=$ biocontainer; Cont $=$ container; $\mathrm{NF}=$ nonfertilizing; Synth = synthetic; PP = petroleum-based polypropylene.

For pepper and tomato, all of the treatments that included a bio-based component were equally or more effective than the synthetic control treatment $[(\mathrm{PP}$ container + Synthetic fertilizer) + Synthetic fertilizer] in facilitating health, growth, and fruit production (Fig. 3). There were no differences in scores of the health rating for any of the treatments, but only treatments that included a bio-based fertilizer (crushed fertilizing biocontainer or biopolymer fertilizer) in the garden phase received the highest possible mean score (100) for health rating. For shoot dry weight, the synthetic control $[(\mathrm{PP}$ container + Synthetic fertilizer) + Synthetic fertilizer] earned a lower score than two of the treatments that included bio-based fertilizer, the [(Fertilizing biocontainer + Biopolymer fertilizer) + Biopolymer fertilizer] treatment and the $[(\mathrm{NF}$ biocontainer + Synthetic fertilizer) + Biopolymer fertilizer] treatment (Fig. 3). All other treatments yielded shoot dry weights that were not different from other treatments that were provided either bio-based fertilizer or the synthetic control fertilizer. There were no differences in fruit production across treatments, except that plants in the treatment that used only the fertilizing biocontainer for nutrient provision in the greenhouse [(Fertilizing biocontainer + No fertilizer $)+$ Biopolymer fertilizer] had a slightly lower score for fruit yield than the treatment that used the fertilizing biocontainer and biopolymer fertilizer in the greenhouse [(Fertilizing biocontainer + Biopolymer fertilizer) + Fertilizing biocontainer]

For marigold and petunia, health ratings were not different across treatments except that the plants that were grown in a fertilizing biocontainer without supplemental fertilizer in the greenhouse, then provided biopolymer fertilizer in the garden [ $(\mathrm{Fer}-$ tilizing biocontainer + No fertilizer $)+$ Biopolymer fertilizer] were slightly less healthy than plants grown in the full control treatment [(PP container + Synthetic fertilizer) + Synthetic 
fertilizer] (Fig. 3). Treatments that produced the highest scores for shoot dry weight were $[$ (Fertilizing biocontainer + No fertilizer $)+$ Fertilizing biocontainer $],[(\mathrm{PP}$ container + Biopolymer fertilizer $)+$ Synthetic fertilizer], and [ (PP container + Synthetic fertilizer $)+$ Synthetic fertilizer]. However, only one treatment [(Fertilizing biocontainer + No fertilizer $)+$ Biopolymer fertilizer] resulted in scores that were significantly lower than these (Fig. 3). There were more differences across treatments for scores of flower production than for the other two metrics. Two of the control treatments, $[(\mathrm{PP}$ container + Biopolymer fertilizer) + Synthetic fertilizer $]$ and [(PP container + Synthetic fertilizer) + Synthetic fertilizer], had higher scores for flower production than did four of the other treatments that had a bio-based fertilizer type applied during the garden phase.

Based on results collected after the garden phase, it appears that the bio-based fertilizers (fertilizing biocontainers and pelletized biopolymer fertilizer) evaluated in our research may be slightly more effective with pepper and tomato than they are with marigold and petunia. The greatest differences between the results for the bio-based fertilizer types and the synthetic CRF control were seen in the number of flowers produced by the end of the garden phase, with some of the bio-based treatment combinations leading to fewer flowers (Fig. 3). Results of most other measurements indicate that the biopolymer-based fertilizers are similarly effective as synthetic CRF for providing nutrients to garden and bedding crops (Table 1, Fig. 3).

In Expt. 2, evaluations of pelletized biopolymer fertilizer and biopolymer fertilizer spikes demonstrated the potential for using these products to provide nutrients for container ornamentals after production and sale, when consumers would be maintaining the plants for aesthetic uses. In both container sizes (13-inch planter and 12 -inch hanging basket), all treatments that included fertilizer (pelletized biopolymer fertilizer, biopolymer fertilizer spikes, and the synthetic CRF) facilitated better health and size (shoot dry weight) than did the no-fertilizer control treatment (Table 2). Results specific to 13-inch planters show that there were no differences between the health and shoot dry weights of plants provided with biofertilizer pellets and those provided with synthetic CRF at either application amount. Health ratings and shoot dry weights of plants treated with biofertilizer spikes were lower than those treated with synthetic
CRF, and health ratings were slightly lower for plants that were fertilized with biofertilizer spikes than for those that were treated with biofertilizer pellets applied at $100 \%$ of the recommended application amount (Table 2). Results for nutrient contents of shoots confirm the uptake of $\mathrm{N}$ from the fertilizers, with shoots of plants in all treatments provided with fertilizer showing higher $\mathrm{N}$ content than those receiving the no-fertilizer control treatment. The uptake of $\mathrm{N}$ from biofertilizer pellets was almost as high as that from the synthetic CRF. Nitrogen uptake from the biofertilizer spikes was lower than that from pellets. The $\mathrm{P}$ and $\mathrm{K}$ contents of plants that received the two biofertilizer types (pellets or spikes) were lower compared with those in the synthetic CRF treatments, results that were expected and consistent with the known lower ratio for these two nutrients in the biopolymer fertilizer.

Results specific to the 12 -inch hanging baskets indicate that the biofertilizer spikes were more effective with this container size and group of species compared with other treatments than they were with the 13inch planters (Table 2). There were no differences in health rating for plants in 12-inch hanging baskets for any of the treatments that were provided with fertilizer (pelletized

Table 2. Health rating, dry weight, and nutrient content [nitrogen $(\mathrm{N})$, phosphorus $(\mathrm{P})$, and potassium (K)] of multiple species in patio planters and hanging baskets and provided with postproduction nutrients from biopolymer fertilizer, biopolymer fertilizer spikes, synthetic controlled-release fertilizer (CRF), or a no-fertilizer control treatment.

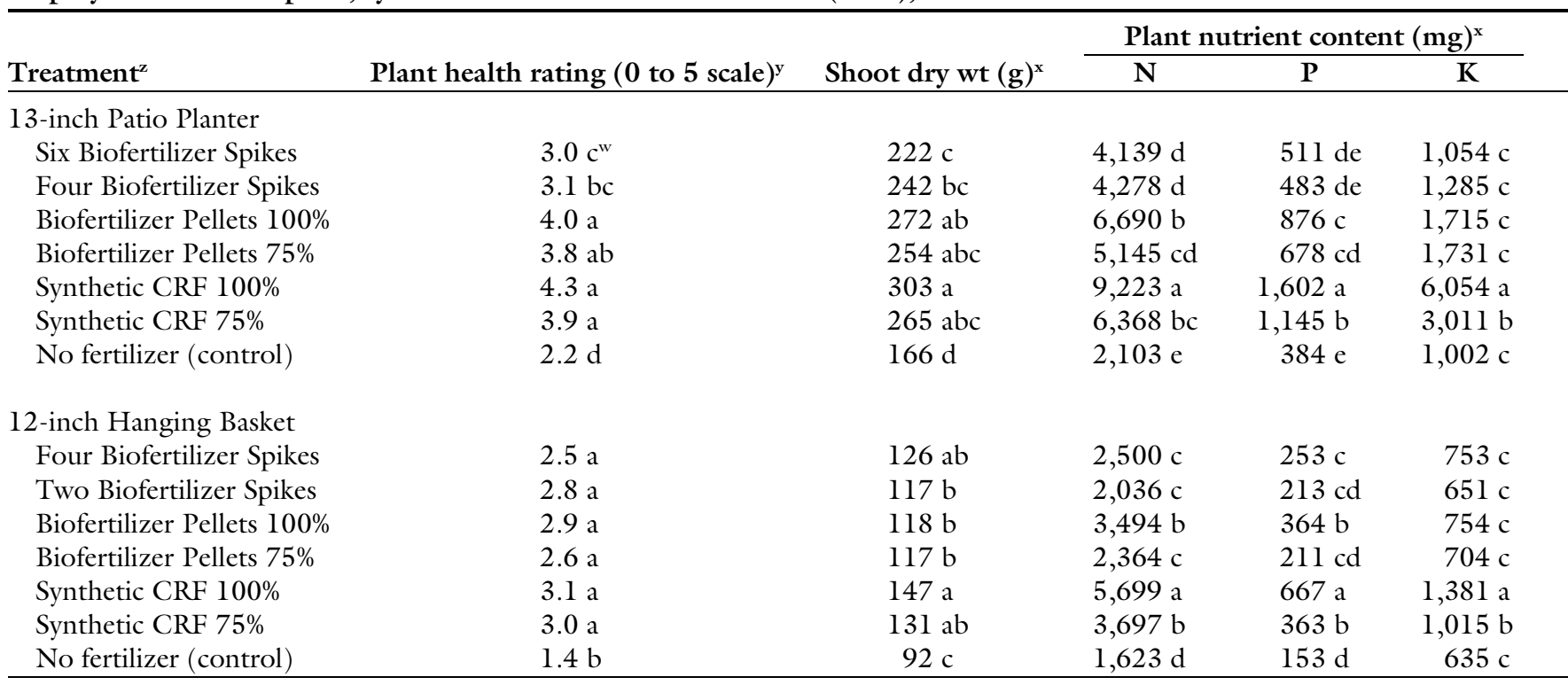

${ }^{\mathrm{z}} \mathrm{Bio}=$ made from bio-based material (nonpetroleum); 1 inch $=2.54 \mathrm{~cm}$.

${ }^{\mathrm{y}}$ Health rating was a visual rating by two experienced horticulturists on a scale of $0=$ worst to $5=$ best.

${ }^{\mathrm{x}} \mathrm{l} \mathrm{g}=0.0353 \mathrm{oz}, \mathrm{l} \mathrm{mg}=3.5274 \times 10^{-5} \mathrm{oz}$.

${ }^{\mathrm{w}}$ Means within a column followed by the same letter are not different according to Tukey-Kramer honestly significant difference test at $P \leq 0.05(n=7)$. Results for patio planters and hanging baskets were analyzed separately. 
biopolymer fertilizer, biopolymer fertilizer spikes, and the synthetic CRF), but health ratings for these treatments were all higher than those of the control with no fertilizer provided. Results for shoot dry weight of plants in 12-inch hanging baskets show that average dry weights were greater for plants provided with synthetic CRF at the $100 \%$ application amount than for those that received biofertilizer pellets at $75 \%$ and $100 \%$ amounts and biofertilizer spikes at the lower application amount (two spikes). Dry weights of plants that received biofertilizer spikes at the higher application amount (four spikes) were not different from those that received the synthetic CRF at $100 \%$. All of the biofertilizer treatments (pellets and spikes at both application amounts) facilitated growth that was comparable with that of plants provided with synthetic CRF at the $75 \%$ application amount (Table 2). The pattern of results for nutrient contents of shoots was similar for plants in 12-inch hanging baskets compared with those in the 13inch planters. In 12 -inch hanging baskets, all plants provided with fertilizer showed greater shoot $\mathrm{N}$ content than those receiving the no-fertilizer control treatment. Shoot N content was much higher for plants that received synthetic CRF at the $100 \%$ application amount than for plants in any other treatment (Table 2), possibly indicating that the synthetic CRF provided at this application amount may lead to luxury consumption of $\mathrm{N}$, which would constitute an inefficient and potentially wasteful level of nutrient provision (Ingestad, 1974). This seems especially likely considering that the health ratings of plants in this treatment were not higher than the ratings of plants that received other treatments containing fertilizer (both application amounts of biofertilizer pellets and spikes, and the synthetic CRF at $75 \%$ ).

Results of our experiments demonstrate the effectiveness of biopolymer horticultural products for sustainable production of quality greenhouse crops, and demonstrate for the first time the effectiveness of pelletized biopolymer fertilizer for providing nutrients to plants in a garden setting (Table 1; Fig. 3). Favorable results with plants in hanging baskets and patio planters constitute proof-of-concept that pelletized biopolymer fertilizer and biopolymer fertilizer spikes are effective for providing nutrients to containerized plants during postproduction growth and maintenance culture (Table 2). One of the factors that must be considered when comparing the effectiveness of biopolymer fertilizers to that of synthetic fertilizers in our study is that fertilizer treatments were set to provide equal amounts of $\mathrm{N}$. By setting the treatments in this way, the experiments arbitrarily caused biopolymer fertilizers to be applied at lower amounts of $\mathrm{P}$ and $\mathrm{K}$. This factor may explain some, or perhaps most, of the lower results obtained for plants provided with biopolymer fertilizers compared with those provided with synthetic CRF. Although the biopolymer fertilizer materials used in this study have been improved from their original form by making small changes to the formulations (McCabe et al., 2016a, 2016b; Schrader et al., 2013), at this time the fertilizers are still considered to be in early stages of product development. It is likely that future research and development will produce formulations that will be equally effective to that of synthetic CRF for growing horticulture crops in containers and in the garden, while still being much more sustainable than synthetic fertilizer (Montalbo-Lomboy et al., 2016).

For growers and consumers that are interested in being as sustainable as possible with culture and growth of bedding plants, use of fertilizing biocontainers with no additional fertilizer may be the best approach. Although plants grown in fertilizing biocontainers with no additional fertilizer were sometimes smaller and slightly less healthy at the end of greenhouse production, plants grown by this method and installed in the garden with only the used container to provide additional nutrients [(Fertilizing biocontainer + No fertilizer) + Fertilizing biocontainer] were equally healthy and of equal size (shoot dry weight) to those that received synthetic fertilizer in the greenhouse and garden (Fig. 3). For certain crops (short- to medium-cycle bedding plants, for example), the fertilizing biocontainers could simplify plant production, reduce inputs, and eliminate landfill disposal of the container. They could eliminate the labor and cost of supplemental fertilizer application, they could provide additional fertilizer nutrients in the garden or flower bed when the container is removed, crushed, and installed under the plant, and they could divert the end-of-life disposal of the containers from the landfill to the garden soil where they could degrade to organic matter. All of these features and functions could potentially improve both efficiency and sustainability during the culture of vegetable and floriculture crops.

\section{Literature cited}

Bhamra, T. and V. Lofthouse. 2007. Design for sustainability: A practical approach. Gower Publ., Aldershot, England.

Broschat, T.K. 1995. Nitrate, phosphate, and potassium leaching from containergrown plant fertilized by several methods. HortScience 30:74-77.

Bryson, G.M., H.A. Mills, D.N. Sasseville, J.B. Jones, Jr., and A.V. Barker. 2014. Plant analysis handbook III: A guide to sampling, preparation, analysis and interpretation for agronomic and horticultural crops. Micro-Macro Publ., Athens, GA.

Calabria, L., N. Vieceli, O. Bianchi, R.V.B. de Oliveria, I. doNascimento Filho, and V. Schmidt. 2012. Soy protein isolate/poly (lactic) acid injection-molded biodegradable blends for slow release of fertilizers. Ind. Crops Prod. 36:41-46.

Chappell, M. and G.W. Knox. 2012. Alternatives to petroleum-based containers for the nursery industry. Univ. Georgia Coop. Ext. Bul. 1407.

Ingestad, T. 1974. Towards optimum fertilization. Ambio 3(2):49-54

Kratsch, H.A., J.A. Schrader, K.G. McCabe, G. Srinivasan, D. Grewell, and W.R. Graves. 2015. Performance and biodegradation in soil of novel horticulture containers made from bioplastics and biocomposites. HortTechnology 25:119-131.

LeCompte, C. 2013. Fertilizer plants spring up to take advantage of U.S.'s cheap natural gas. Scientific American. 21 Mar. 2018. <https://www.scientificamerican. com/article/fertilizer-plants-grow-thanks-tocheap-natural-gas>.

McCabe, K.G., J.A. Schrader, S. Madbouly, D. Grewell, and W.R. Graves. 2014. Evaluation of biopolymer-coated fiber containers for container-grown plants. HortTechnology 24:439-448.

McCabe, K.G., J.A. Schrader, C.J. Currey, D. Grewell, and W.R. Graves. 2016a. Soycomposite biocontainers allow for reduced fertilizer inputs during container-crop production. HortScience 51:927-934. 
McCabe, K.G., C.J. Currey, J.A. Schrader, D. Grewell, J. Behrens, and W.R. Graves. 2016b. Pelletized soy-based bioplastic fertilizers for container-crop production. HortScience 51:1417-1426.

McCabe, K.G., J.A. Schrader, and C.J. Currey. 2016c. Performance of bioplastic and biocomposite containers in greenhouse experiments, p. 97-118. In: J.A. Schrader, H.A. Kratsch, and W.R. Graves (eds.). Bioplastic container cropping systems: Green technology for the green industry. Sustainable Hort. Res. Consortium, Ames, IA.

Mengel, K. and E.A. Kirkby. 2001. Principles of plant nutrition. 5th ed. Kluwer Academic Publ., Dordrecht, The Netherlands.

Montalbo-Lomboy, M., J.A. Schrader, and D. Grewell. 2016. Cradle-to-gate life cycle assessment of bioplastic horticulture containers and comparison to standard petroleum plastic containers, p. 249-273. In: J.A. Schrader, H.A. Kratsch, and W.R. Graves (eds.). Bioplastic container cropping systems: Green technology for the green industry. Sustainable Hort. Res. Consortium, Ames, IA.
Pyle, D. 1999. Data preparation for data mining. Morgan Kaufmann Publ., San Francisco, CA.

Sawyer, J.E., H.M. Hanna, and D. Petersen. 2010. Farm energy: Energy conservation in corn nitrogen fertilization. Agr. Environ. Ext. Publ. Book 196. 3 Mar. 2018. $<$ http://lib.dr.iastate.edu/extension_ag_ pubs/196>.

Schrader, J.A. 2013. Report on the annual consumption of plastics for specialty-crop containers in the United States. 21 Mar. 2018. <http://www.public.iastate.edu/ $\sim$ bi oplastic/S upplementary/ AnnualPlastic.html>.

Schrader, J.A. 2016a. Bioplastics for horticulture: An introduction, p. 126. In: J.A. Schrader, H.A. Kratsch, and W.R. Graves (eds.). Bioplastic container cropping systems: Green technology for the green industry. Sustainable Hort. Res. Consortium, Ames, IA.

Schrader, J.A. 2016b. Status of bioplastic container cropping systems technology: August 2016, p. 275-292. In: J.A. Schrader, H.A. Kratsch, and W.R. Graves (eds.). Bioplastic container cropping systems: Green technology for the green industry. Sustainable Hort. Res. Consortium, Ames, IA.

Schrader, J.A., H.A. Kratsch, and W.R. Graves (eds.). 2016. Bioplastic container cropping systems: Green technology for the green industry. Sustainable Hort. Res. Consortium, Ames, IA.

Schrader, J.A., G. Srinivasan, D. Grewell, K.G. McCabe, and W.R. Graves. 2013. Fertilizer effects of soy-plastic containers during crop production and transplant establishment. HortScience 48:724-731.

Wilson, C., J. Albano, M. Mozdzen, and C. Riiska. 2010. Irrigation water and nitrate- $\mathrm{N}$ loss characterization in southern Florida nurseries: Cumulative volumes, runoff rates, nitrate- $\mathrm{N}$ concentrations and loadings, and implications for management. HortTechnology 20:325-330.

Yeager, T., R. Wright, D. Fare, C. Gilliam, J. Johnson, T. Bilderback, and R. Zondag. 1993. Six state survey of container nursery nitrate nitrogen runoff. J. Environ. Hort. 11:206-208. 